\title{
La equidad horizontal en la tributación de las cooperativas en México
}

\author{
(Horizontal equity in the taxation of cooperatives in Mexico)
}

\author{
Graciela Lara Gómez ${ }^{1}$ \\ Universidad Autónoma de Querétaro (México)
}

Sumario: 1. Introducción. 2. Aproximación teórica a la equidad tributaria. 3. Metodología. 4. Desarrollo. 4.1. Las cooperativas y su fiscalidad. 4.1.1. Tratamiento tributario para las cooperativas de consumo y de ahorro y préstamo. 4.1.2. Tratamiento fiscal para las cooperativas de producción. 4.2. Las cooperativas a la luz de la equidad tributaria. 5. Conclusiones. 6 . Referencias bibliográficas.

Summary: 1. Introduction. 2. Theoretical approach to tax equity. 3. Methodology. 4. Development. 4.1. Cooperatives and their taxation. 4.1.1. Tax treatment for consumer and savings \& loan cooperatives. 4.1.2. Tax treatment for production cooperatives. 4.2. Cooperatives in light of tax equity. 5. Conclusions. 6. Bibliographic references.

Resumen: La finalidad del artículo fue efectuar un análisis de las cooperativas mexicanas a la luz del principio de equidad tributaria. Se parte de que éstas poseen un tratamiento diferenciado según la Ley del Impuesto Sobre la Renta, por lo que se busca dilucidar los fundamentos jurídicos que apoyan tal circunstancia. Por tanto, se efectuó una aproximación teórica basada en la equidad y su enfoque horizontal, considerando que todas las cooperativas deben ser iguales ante la ley. El método de investigación utilizado fue el exegético, a efecto de ubicar los argumentos que el legislador consideró en la creación de la norma, por lo que además se analizaron las resoluciones de la Corte referidas a la fiscalidad de las cooperativas.

Palabras clave: Justicia, impuestos, equidad horizontal, cooperativas.

Abstract: The purpose of the article is to develop an analysis of Mexican cooperatives in light of the principle of tax equity. It is assumed that they have a differentiated treatment according to the Income Tax Law, for that reason, we look for empirical evidence in order to clarify the legal grounds that support such circumstance. Therefore, a theoretical approach based on equity and its horizontal approach was made, considering that all cooperatives must be

1 Email: glara@uaq.mx,glaragomez@yahoo.com.mx

Boletín de la Asociación Internacional de Derecho Cooperativo ISSN: 1134-993X • ISSN-e: 2386-4893, No. 53/2018, Bilbao, págs. 251-273 
equal before the law. The method of research is the exegetical and it was used to locate the arguments that the legislator considered in the creation of the norm, reason why in addition, we consider also the resolutions of the Court referred to the taxation of the cooperatives.

Keywords: Justice, taxes, horizontal equity, cooperatives. 


\section{Introducción}

Autores como Arnaiz Amigo (1979) y Rojas Coria (1984) afirman que la existencia de las cooperativas en México es antigua, por lo que el calpulli y el tequio son importantes antecedentes de la época pre colonial. Algunos vestigios se encontraron entre los aztecas, quienes idearon el calpulli como una forma de trabajar la tierra de manera comunitaria, mientras que el tequio se concibió como una contribución para el beneficio común, que consistió en proporcionar servicios sin remuneración alguna.

Rojas Coria (1984) señala que las cajas de comunidades indígenas, los pósitos, entre otros, fueron organizaciones que surgieron en la época Colonial y según Arnaiz Amigo (1979) fue a mediados del siglo XIX que el cooperativismo cobró importancia, pero en ese tiempo no surgieron organizaciones de gran trascendencia.

Un evento relevante ocurrió en la última etapa del siglo XIX, cuando se reconoció jurídicamente a las cooperativas en México a través del Código de Comercio (1889), el que fue publicado con fecha 15 de septiembre de 1889 y cuya vigencia inició el $1 .^{\circ}$ de enero de 1890. En dicha norma se reconoció a las cooperativas como un tipo de sociedad mercantil y tal característica ha prevalecido hasta la actualidad, integrando a dichas sociedades en la fracción VI del artículo $1 .^{\circ}$ de la Ley General de Sociedades Mercantiles (2016).

La legislación vigente fue promulgada el 3 de agosto de 1994 (Ley General de Sociedades Cooperativas, 1994), reconociendo únicamente a las cooperativas de consumo y producción. En años posteriores se integró a la cooperativa de ahorro y préstamo, (Ley General de Sociedades Cooperativas, 2009) a través de una reforma que buscaba dar certeza jurídica a las entidades que hasta entonces eran conocidas como cajas populares. Actualmente las tres figuras jurídicas se encuentran contempladas en la normatividad tributaria a través de leyes que gravan los ingresos (Ley del Impuesto Sobre la Renta, 2016) y normas que gravan el consumo como el Impuesto al Valor Agregado.

Por lo mencionado, en este artículo se analiza a la luz del principio de equidad tributaria, el tratamiento fiscal en materia del Impuesto Sobre la Renta (ISR) para las cooperativas en México, buscando dilucidar ¿Por qué entre las cooperativas existe un tratamiento fiscal diferenciado?

Para dar respuesta al cuestionamiento, en un primer momento se llevó a cabo una aproximación teórica sobre el principio de justicia, para luego definir y establecer los tipos de equidad tributaria, además del significado asumido en los criterios de la Suprema Corte de Justicia de 
la Nación (SCJN). Luego con apoyo en el método exegético se estudió el sentido legal de las disposiciones que liberan o gravan con el ISR las actividades realizadas por los tres tipos de cooperativas y además se analizaron las exenciones, reducciones y otros estímulos que las benefician.

\section{Aproximación teórica a la equidad tributaria}

Diversos autores como Arrioja Vizcaíno (2014), Rawls (2010), Gómez Sabaini, Santiere, \& Rossignolo (2002) y Stiglitz (1995) afirman que la expresión equidad se encuentra contenida en la máxima de justicia, la que es concebida según Rawls (2010) como la virtud suprema y primigenia de las instituciones, entonces las instituciones serán justas cuando no se efectúen diferenciaciones arbitrarias y la justicia dependerá de cómo se estipulan los deberes, los derechos, las oportunidades económicas y las condiciones sociales para los ciudadanos.

La justicia se entiende como un «Principio moral que lleva a dar a cada uno lo que le corresponde o pertenece» (DRAE, 2014, 1) la que surge a partir del derecho, la razón y la equidad. Entonces la equidad significa la "disposición del ánimo que mueve a dar a cada uno lo que merece.» (DRAE, 2014, 1). Desde una perspectiva jurídica, Arrioja Vizcaíno $(2014,259)$ contribuye diciendo que la equidad se logra «tratando igual a los iguales y en forma desigual a los que no se encuentran en igualdad de circunstancias».

Evidentemente el significado de equidad tiene una fuerte carga de subjetividad que obstaculiza la formulación de normas jurídicas de carácter fiscal, a efecto de decidir quién se ubica en la hipótesis normativa y en qué condiciones debe pagar más que otros (Stiglitz, 1995). Ante la subjetividad de diferenciar lo que se concibe como equitativo, Rawls (2010) propone que este concepto puede visualizarse considerando el estado en que se encuentra la sociedad en general, ya que la misma estará en mejores condiciones, si lo está el ciudadano que se encontraba en una realidad desfavorable como consecuencia de una política determinada.

Por tanto, la madurez de una sociedad puede ser determinada a partir de la equidad, no únicamente en las relaciones interpersonales, sino en la sociedad en su conjunto (Gómez-Sabaini, Santiere, \& Rossignolo, 2002), ya que como lo indica Arrioja Vizcaíno (2014) y Rawls (2010) la equidad persigue el bienestar de las personas que se encuentren en desventaja.

Stiglitz (1995) recuerda que la equidad puede ser vista a partir de dos perspectivas: la horizontal y la vertical, lo que es útil para diferen- 
ciar a los contribuyentes que no cuentan con la misma capacidad contributiva, por lo que establecer diferentes categorías para el pago del tributo ubicaría a los ciudadanos en condiciones de equidad.

Cabe señalar que la característica redistributiva de los tributos está relacionada con la equidad vertical, lo que conduce a que los individuos con mayor capacidad contributiva cubran proporcionalmente mayores tributos. En la equidad horizontal los gravámenes deben afectar de igual manera a los que tienen la misma capacidad contributiva, lo que media en la legitimación de un sistema tributario y en consecuencia, este tipo de equidad posee un papel indirecto en la redistribución del ingreso (Jorrat, 2011).

Con lo mencionado, se asume que un sistema es equitativo horizontalmente si los sujetos son iguales en todos los aspectos y reciben idéntico trato, mientras que será equitativo verticalmente si considera que algunas personas tienen mejores condiciones que otros para realizar el pago de los tributos, por lo que de ser así deben pagarlos (Stiglitz, 1995).

Por tanto, para determinar qué tan equitativo es un tributo, debe identificarse la capacidad contributiva con la que cuenta cada sujeto pasivo, entendiendo que existen algunos que poseen la misma o similar situación contributiva y otros que se encuentran en condiciones diferentes (Figura 1).

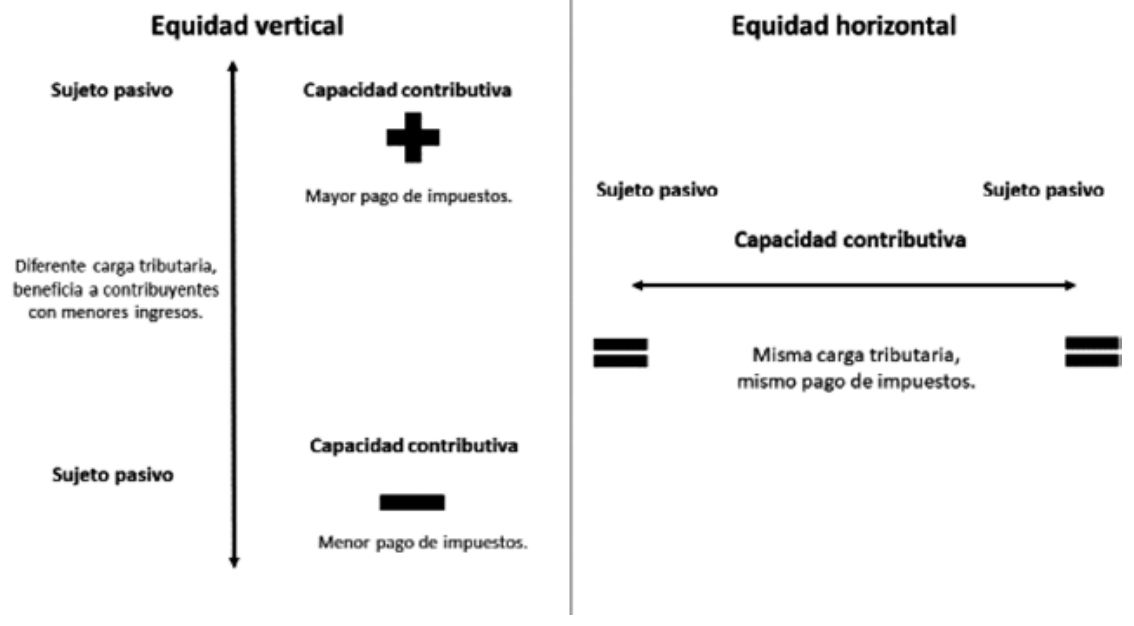

Fuente: Elaboración propia.

Figura 1

Equidad tributaria vertical y horizontal 
No obstante, es significativo señalar que tiene una importante complejidad identificar sujetos con idéntica capacidad contributiva, como se esperaría en la equidad horizontal, lo que implica que dos individuos con el mismo ingreso tendrían el mismo tratamiento tributario y la misma situación económica aun después del pago del impuesto (Jorrat, 2011).

En este orden de ideas, resulta relevante recordar los razonamientos proveídos por la Corte, donde se indica el alcance de los principios jurídicos contenidos en la Constitución Política de los Estados Unidos Mexicanos (2017), -incorporados desde 1917- determinando el alcance del significado de la equidad y la proporcionalidad tributarias (SCJN, 1984, 113), tal como se indica a continuación:

PROPORCIONALIDAD Y EQUIDAD TRIBUTARIAS ESTABLECIDAS EN EL ARTÍCULO 31, FRACCIÓN IV, CONSTITUCIONAL. El artículo 31, fracción IV, de la Constitución establece los principios de proporcionalidad y equidad en los tributos. La proporcionalidad radica, medularmente, en que los sujetos pasivos deben contribuir a los gastos públicos en función de su respectiva capacidad económica, debiendo aportar una parte justa y adecuada de sus ingresos, utilidades o rendimientos. Conforme a este principio, los gravámenes deben fijarse de acuerdo con la capacidad económica de cada sujeto pasivo, de manera que las personas que obtengan ingresos elevados tributen en forma cualitativa superior a los de medianos y reducidos recursos. El cumplimiento de este principio se realiza a través de tarifas progresivas, pues mediante ellas se consigue que cubran un impuesto en monto superior los contribuyentes de más elevados recursos. Expresado en otros términos, la proporcionalidad se encuentra vinculada con la capacidad económica de los contribuyentes que debe ser gravada diferencialmente, conforme a tarifas progresivas, para que en cada caso el impacto sea distinto, no sólo en cantidad, sino en lo tocante al mayor o menor sacrificio reflejado cualitativamente en la disminución patrimonial que proceda, y que debe encontrarse en proporción a los ingresos obtenidos. El principio de equidad radica medularmente en la igualdad ante la misma ley tributaria de todos los sujetos pasivos de un mismo tributo, los que en tales condiciones deben recibir un tratamiento idéntico en lo concerniente a hipótesis de causación, acumulación de ingresos gravables, deducciones permitidas, plazos de pago, etcétera, debiendo únicamente variar las tarifas tributarias aplicables, de acuerdo con la capacidad económica de cada contribuyente, para respetar el principio de proporcionalidad antes mencionado. La equidad tributaria significa, en consecuencia, que los contribuyentes de un mismo impuesto deben guardar una situación de igualdad frente a la norma jurídica que lo establece y regula. 
Con lo expresado por la Corte se confirma que la equidad tributaria horizontal y vertical tiene una relación importante con el principio de proporcionalidad incluido en la Constitución Política de los Estados Unidos Mexicanos (2017), donde se justifica la importancia de la capacidad económica de los individuos para contribuir para el gasto público; y cuyo eje debe caracterizarse por tratar de beneficiar a los estratos con menores ingresos y gravar en mayor medida a aquellos ciudadanos con mayor capacidad económica.

Por tanto, los sistemas fiscales tienen como objetivo conseguir un impacto redistributivo definido con impuestos que graven los ingresos con tasas progresivas, lo que entorpece en la equidad horizontal, donde sujetos con la misma capacidad de pago no enfrentan la idéntica carga tributaria, como ocurriría en la equidad vertical. Entonces, los que tienen mayor capacidad contributiva, también obtienen más oportunidades de infringir el objetivo tributario a través de estrategias de evasión y elusión fiscal (Jiménez, Gómez Sabaini, \& Podestá, 2010).

Para lograr un equilibro y equidad en la carga tributaria que cada sujeto pasivo debe asumir, la teoría económica (Mankiw, 2012), considera como viable y necesaria la introducción de incentivos. En este sentido, diversos autores (Atxabal Rada, 2016; Cracogna, 2004; Alguacil Marí, 2003) han respaldado la necesidad de otorgar incentivos a las cooperativas, explicando que son organizaciones que contribuyen fuertemente al desarrollo económico y social de las regiones en las que se insertan, lo que significa que su sola finalidad debería ser el argumento válido para otorgar un trato diferenciado respecto de otros sujetos pasivos, como es el caso de las empresas de capitales, ya que en sí mismo el otorgamiento de incentivos para las cooperativas es un asunto de justicia tributaria.

\section{Metodología}

La finalidad del artículo fue llevar a cabo el análisis de las cooperativas mexicanas a la luz del principio constitucional de equidad tributaria. Para tal efecto se estableció que la Ley General de Sociedades Cooperativas (2009) reconoce tres organizaciones: las cooperativas de ahorro y préstamo, las cooperativas de consumo y las cooperativas de producción. Por tanto, se parte de que el tratamiento fiscal que se aplica a dichas organizaciones es diferenciado y por tanto inequitativo, según los preceptos normativos de la Ley del Impuesto Sobre la Renta (2016), por lo que se busca dilucidar las razones jurídicas que sustentan tal diferenciación. 
Tomando en cuenta lo mencionado, se realizó una aproximación teórica sobre el principio de equidad y su enfoque horizontal, considerando que por tratarse de la misma figura jurídica - cooperativa- el tratamiento debiera ser el mismo, es decir, aplicaría la equidad horizontal, ya que por su doble finalidad social y económica tendría que ser beneficiada con exoneraciones u otro tipo de incentivos que estarían justificados constitucional y socialmente.

Asimismo, se atendió a la aproximación basada en el método de investigación exegético, que se apoyó en el análisis de las leyes fiscales vigentes y en la jurisprudencia de la Corte, a efecto de identificar los argumentos expresados a través de las cooperativas como sujetos del impuesto y los fallos emitidos por los jueces.

\section{Desarrollo}

Para determinar cuál es el esquema tributario que aplica a las cooperativas, se auxilió de algunos preceptos contenidos en la Ley General de Sociedades Cooperativas (2009) y posteriormente se examinó el tratamiento fiscal que para los tres tipos de cooperativas establece la Ley del Impuesto Sobre la Renta (2016). Adicionalmente, se estudiaron las jurisprudencias de la SCJN que han dirimido controversias centradas en el principio de equidad tributaria y su aplicación en las sociedades objeto de estudio.

\subsection{Las cooperativas y su fiscalidad}

La Constitución Política de los Estados Unidos Mexicanos (2017, 25) contempla a las sociedades cooperativas como integrantes del sector social de la economía (artículo 25), en el precepto se insta al Estado para que establezca las condiciones suficientes para su pleno desarroIlo, de tal manera que está obligado a crear los dispositivos jurídicos necesarios para su instrumentación, es decir «La ley establecerá los mecanismos que faciliten la organización y la expansión de la actividad económica del sector social».

Es en la Ley General de Sociedades Cooperativas (2009) que integran las disposiciones que rigen actualmente a tales sociedades, por lo que en la norma se incluyen diversas disposiciones que contemplan su existencia jurídica, su forma de constitución, tipos y clases de cooperativas, rol de los socios, administración y demás disposiciones con las que se regula su actividad económica y social. 
En el artículo 2. ${ }^{\circ}$ de la Ley General de Sociedades Cooperativas (2009) se define a la cooperativa como:

Artículo $2 .^{\circ}$ La sociedad cooperativa es una forma de organización social integrada por personas físicas con base en intereses comunes y en los principios de solidaridad, esfuerzo propio y ayuda mutua, con el propósito de satisfacer necesidades individuales y colectivas, a través de la realización de actividades económicas de producción, distribución y consumo de bienes y servicios.

Tal como se desprende del precepto legal, las cooperativas únicamente pueden ser constituidas por personas físicas, cuya finalidad será llevar a cabo actividades a través de organizaciones dedicadas al consumo de bienes y servicios. Dichas organizaciones según el artículo 21 podrán ser de tres clases: de consumidores de bienes y/o servicios, de productores de bienes y/o servicios, y de ahorro y préstamo (Ley General de Sociedades Cooperativas, 2009).

Adicionalmente, en el artículo 23 se prevé que las cooperativas de consumidores podrán llevar a cabo operaciones con terceros y dar oportunidad de que éstos puedan asociarse y en lo que corresponde a las cooperativas de ahorro y préstamo, las mismas se regirán por la Ley para Regular las Actividades de las Sociedades Cooperativas de Ahorro y Préstamo (Ley General de Sociedades Cooperativas, 2009).

Las tres clases de cooperativas se encuentran reguladas en la Ley del Impuesto Sobre la Renta (2016). De tal manera que las cooperativas de ahorro y préstamo así como las de consumo, se ubican en el Título III De las Personas Morales no Lucrativas, en tal apartado se enlistan las personas morales que quedan liberadas del pago del impuesto al considerarse que su actividad no tiene fin de lucro; tal disposición que es concordante con lo previsto en la Ley General de Sociedades Cooperativas (2009). Mientras que en el Título II De las Personas Morales se localizan a las sociedades que quedan sujetas al ISR, como es el caso de las cooperativas de producción, lo que es divergente a lo establecido por la legislación cooperativa, al no considerar a esta última en las mismas condiciones que a las primeras que se encuentran liberadas del ISR (Figura 2).

Los supuestos que liberan o gravan a las cooperativas, así como los incentivos expresados a partir de las exenciones, las reducciones y los diferimientos se explican en los siguientes parágrafos. 


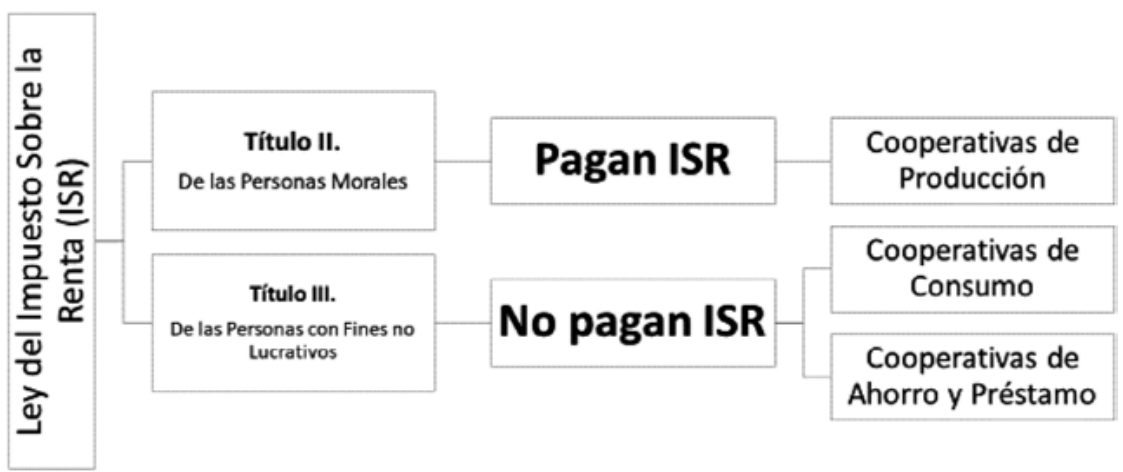

Fuente: Elaboración propia, con base en la Ley del Impuesto Sobre la Renta (2016).

Figura 2

Tipos de cooperativas y su tributación

\subsubsection{Tratamiento tributario para las cooperativas de CONSUmo Y DE AHORRO Y PRÉSTAMO}

En el Título III se ubica a las Cooperativas de Consumo y a las de Ahorro y Préstamo, concretamente en el artículo 79 de la Ley del Impuesto Sobre la Renta (2016), donde se expresa la liberación del impuesto en las fracciones VII y XIII, dado que ambos tipos de sociedades son consideradas como no lucrativas, lo que es concordante con lo establecido en la Ley General de Sociedades Cooperativas (2009).

El texto legal contenido en la Ley del Impuesto Sobre la Renta (2016, 93-94) que indica la liberación del ISR se transcribe enseguida:

Artículo 79. No son contribuyentes del impuesto sobre la renta, las siguientes personas morales:

(...)

VII. Sociedades cooperativas de consumo.

XIII. Las instituciones o sociedades civiles, constituidas únicamente con el objeto de administrar fondos o cajas de ahorro, y aquéllas a las que se refiera la legislación laboral, así como las sociedades cooperativas de ahorro y préstamo a que se refiere la Ley para regular las actividades de las sociedades cooperativas de ahorro y préstamo.

Cabe mencionar que si los socios de las cooperativas reguladas en el Título III - no contribuyentes - de la Ley del Impuesto Sobre la Renta (2016) determinan decretar la distribución de remanentes, es en- 
tonces que se causa el impuesto a cargo de cada uno de los asociados y la obligación de la cooperativa será exclusivamente retener el ISR y pagarlo a la Secretaría de Hacienda y Crédito Público. Adicionalmente, se prevé que si las cooperativas incurren en omisiones, tales como la falta de registro de compras o no haberlas efectuado, omitir ingresos, efectuar erogaciones que tengan el carácter de no deducibles o bien, otorgar préstamos a socios de cooperativas de consumo y a familiares del socio en línea recta, el importe de dichos conceptos se considerará como ingreso distribuible, por el que deberá pagarse el ISR, dicho pago se considerará como impuesto definitivo.

\subsubsection{Tratamiento fiscal para las Cooperativas de Producción}

En lo que atañe a las cooperativas de producción la Ley del Impuesto Sobre la Renta (2016) contempla dos tratamientos, uno que está contenido en el Título II De las Personas Morales y uno más que representa una opción para el pago del ISR y que se ubica en el Título VII De los Estímulos Fiscales. En ambos casos se considera a las cooperativas de producción como contribuyentes sujetos al pago del ISR, no obstante, en los dos títulos se incluyen incentivos que reducen la carga tributaria de dichas sociedades, pero en ningún caso quedan liberadas del ISR. Los incentivos contenidos en el Título II se expresan a través de exoneraciones y reducciones del impuesto, mientras que en el Título VII se contempla el diferimiento del ISR y la posibilidad de efectuar el cálculo del impuesto de acuerdo con el Título IV que grava a las personas físicas.

Por tanto, se inicia presentando el mecanismo para determinar el gravamen y en su caso las exoneraciones aplicables de conformidad con el Título II, de tal forma que se analizan las disposiciones contenidas en el Capítulo VIII, denominado Régimen de actividades agrícolas, ganaderas, silvícolas y pesqueras, indicando en el artículo 74 de la Ley del Impuesto Sobre la Renta (2016) qué características deberán tener las cooperativas que se incluyan en dicho apartado.

De tal manera que en el texto legal antes mencionado se expresa:

Artículo 74. Deberán cumplir con sus obligaciones fiscales en materia del impuesto sobre la renta conforme al régimen establecido en el presente Capítulo, los siguientes contribuyentes:

I. Las personas morales de derecho agrario que se dediquen exclusivamente a actividades agrícolas, ganaderas o silvícolas, las sociedades cooperativas de producción y las demás personas morales, que se dediquen exclusivamente a dichas actividades. 
II. Las personas morales que se dediquen exclusivamente a actividades pesqueras, así como las sociedades cooperativas de producción que se dediquen exclusivamente a dichas actividades.

El dispositivo legal prevé que se considera dedicación exclusiva a las actividades mencionadas en las fracciones anteriores, cuando se obtengan ingresos que representen por lo menos el 90\% de sus actividades, sin incluir la trasmisión de propiedad de activos fijos que hayan sido utilizados para su operación.

Asimismo, se menciona que tratándose de las personas morales dedicadas exclusivamente a actividades agrícolas, ganaderas silvícolas o pesqueras, no pagarán el impuesto por los ingresos que provengan de sus actividades, por hasta por un monto equivalente a 20 veces el salario mínimo general elevando al año² (Unidades de Medida Actualizadas-UMAs) por cada uno de sus integrantes, sin que dicho importe exceda 200 UMAs por el total de sus integrantes. Adicionalmente, si los ingresos obtenidos son inferiores de 423 UMAs por cada socio, la cooperativa tendrá derecho a reducir el impuesto a su cargo en un $30 \%$, siempre que la totalidad de los ingresos no excedan de 4230 UMAs, por el excedente deberá pagarse el ISR a la tasa del 30\% sin reducción alguna (Ley del Impuesto Sobre la Renta, 2016).

Como deriva de los preceptos citados, la reducción del ISR a cargo de las cooperativas de producción se encuentra limitada a aquellas sociedades que realicen actividades agrícolas, ganadera, silvícolas y pesqueras. Por tanto, las cooperativas que se dediquen a actividades diferentes de las mencionadas, pagarán el 30\% por concepto del ISR anual sobre su resultado fiscal (utilidad gravable), como si se tratara de una sociedad de capitales.

Cabe señalar que el tratamiento que se ha aludido para las cooperativas de producción, data de las reformas aprobadas por el Congreso de la Unión y que entraron en vigor a partir de 2015, por lo que las características de la ley anterior a esa época eran más favorables para las cooperativas. Esto nos lleva a inferir que la reforma fiscal respondió a necesidades recaudatorias, pero también a frenar el uso indebido de las cooperativas de producción a las que ya se habían referido Lara Gómez y Rico Hernández (2008), quienes evidenciaron la utilización de la

2 El 27 de enero de 2016 tuvo lugar una reforma constitucional que instruye a que las leyes que hagan referencia al salario mínimo general, deberán utilizar la Unidad de Medida Actualizada (UMA o UMAs en plural) para determinar los límites de exención u otras referencias en ese sentido. El valor anualizado de la UMA es de 29,402.88 pesos mexicanos, unos 1,247 euros (INEGI, 2018). 
figura jurídica de manera indebida para eludir la carga tributaria simulando la constitución de cooperativas evitando así el pago del ISR, además de la responsabilidad de pagar las aportaciones de seguridad social y los compromisos laborales. Las autoras consideran que fue con la última publicación de la Ley General de Sociedades Cooperativas (1994), que se constituyeron una gran cantidad de cooperativas de producción de servicios dedicadas a la tercerización o subcontratación, construyendo esquemas de simulación fiscal y laboral.

Como se ha mencionado, existe un tratamiento optativo para el pago del ISR a cargo de las cooperativas de producción, mismo que se encuentra incluido en el Título VII De los Estímulos Fiscales, el Capítulo VII De las Sociedades Cooperativas de Producción, las disposiciones de dicho título podrán aplicarse, en lugar de lo establecido en el Título II.

Se establece que las sociedades cooperativas de producción podrán aplicar lo dispuesto en la Sección I del Capítulo II, Título IV que corresponde al tratamiento que se les da a las personas físicas que obtengan ingresos por actividades empresariales y profesionales. En este tenor, en los artículos 194 y 195 de la Ley del Impuesto Sobre la Renta (2016) se contemplan las características y requisitos para que dichas sociedades puedan acceder a los estímulos referidos en los artículos mencionados, mismos que se indican enseguida.

- Las sociedades cooperativas deben estar constituidas únicamente por personas físicas.

- Determinarán el ISR como si se tratarán de personas físicas con actividades empresariales o profesionales, de tal manera que se calculará el impuesto anual por cada uno de los socios, considerando la utilidad gravable que le corresponda a cada socio de acuerdo con su participación en la cooperativa.

- La sociedad cooperativa de producción, no realizará pagos provisionales.

- Podrá diferir el ISR causado, hasta el año en que se distribuya la utilidad a los socios, en caso de que no la distribuyan en los dos ejercicios siguientes pagarán el ISR en los términos del capítulo VII y de distribuirlas, pagarán el impuesto que se haya diferido aplicando una tarifa progresiva (según el artículo 152 de la Ley del Impuesto Sobre la Renta, 2016), además el socio podrá disminuir en su propia declaración anual el ISR que le corresponda pagado por la sociedad.

- En el caso de que la cooperativa invierta en activos financieros diferentes a las cuentas por cobrar de sus clientes o recursos 
para la operación normal, se considerará que se distribuyen utilidades entre sus socios, lo que dará lugar al pago del impuesto.

- Las cooperativas que no distribuyan rendimientos a sus socios, únicamente podrán invertir en bienes que generen más empleos o incluyan a más socios cooperativistas y cuando se otorguen rendimientos y anticipos a los socios, éstos pagarán el impuesto como si se tratará de ingresos asimilados a un servicio personal subordinado.

Cabe mencionar que de conformidad con el Decreto por el que se otorgan medidas de apoyo a la vivienda y otras medidas fiscales (2015), en el cual queda plasmado el estímulo fiscal para las sociedades cooperativas de producción que tributen en los términos del Título VII, Capítulo VII de la Ley de ISR, se establece un periodo adicional de tres años para diferir el impuesto, de tal manera que cada uno de los socios gozará del beneficio hasta por cinco años, en el supuesto de que se determine utilidad gravable en el ejercicio y no sea distribuida. Entre los requisitos que se prescriben en el decreto, se incluye la obligación de invertir el equivalente al monto del impuesto diferido en inversiones productivas y que los préstamos que otorguen a sus socios no excedan del $3 \%$ del total de los ingresos anuales de la sociedad y de rebasar dicho límite se considerará que se distribuyen utilidades, lo que dará lugar a la determinación del ISR.

Con apoyo en los párrafos que anteceden, se establece que las disposiciones contenidas en los Títulos II y VII de la Ley del Impuesto Sobre la Renta (2016) son los aplicables a las cooperativas de producción, por lo que será optativo apegarse al estímulo fiscal que la propia legislación prevé y en su caso diferir el ISR a cargo de los socios hasta por cinco años.

El tratamiento fiscal previsto en ambos títulos para las cooperativas de producción se esquematizan como sigue (Figura 3):

Finalmente, debe señalarse que las cooperativas que hayan optado por dejar de tributar de acuerdo con la opción prevista en el apartado de estímulos fiscales (Título VII), en ningún caso podrán volver a tributar en los términos del mismo, por tanto pagarán el ISR de conformidad con el Título II De las Personas Morales, es decir, aplicando la tasa del $30 \%$ a la utilidad gravable. 


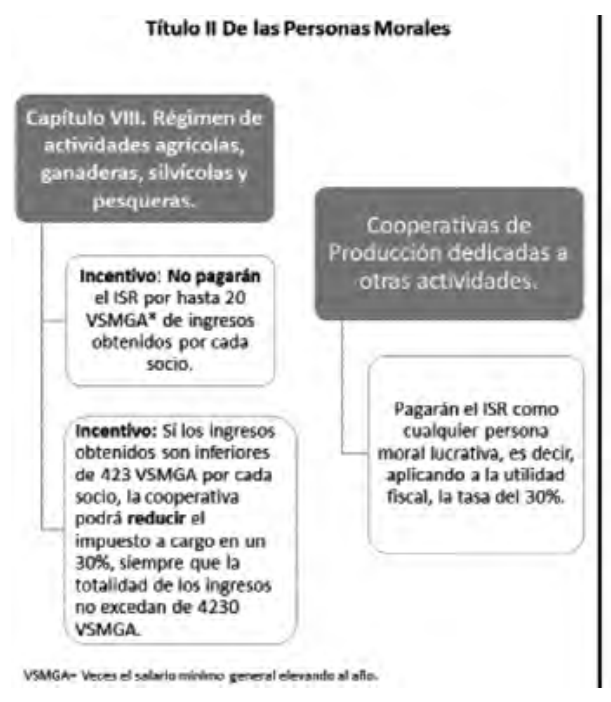

Titulo VII De los Estimulos Fiscales

Capitula VII. De las Sociedades

Fuente: Elaboración propia, con base en la Ley del Impuesto Sobre la Renta (2016).

\section{Figura 3}

Tratamiento fiscal para las cooperativas de producción

\subsection{Las cooperativas a la luz de la equidad tributaria}

Constan razones justificadas para que los ciudadanos aporten con sus impuestos lo suficiente para sufragar el gasto público, ya que como lo indica Rodrigo Ruiz (2003) existen partidarios que propugnan por aplicar un régimen tributario general para las cooperativas, sin hacer diferencias y con ello, dar un tratamiento igualitario a todos los agentes económicos. Pero también pueden encontrase razones argüidas en favor de la liberación del impuesto (Atxabal Rada, 2016; Cracogna, 2004; Alguacil Marí, 2003), dado que en el caso de las cooperativas son éstas las que llevan a cabo un aporte importante al desarrollo económico y social de las comunidades, coadyuvando con el Estado en la solución de problemáticas limitadamente atendidas y participando con la población en su desarrollo integral. Es decir, es necesario que el aspecto tributario se adapte a la realidad económica que prevalece entre las cooperativas mexicanas, ya que existen contribuyentes que merecen ser diferenciados y recibir incentivos, como los expresados a través de las exenciones de impuestos u otros mecanismos que equilibran la carga tributaria. 
Del análisis efectuado sobre el tratamiento tributario para los tres tipos de cooperativas, pudo establecerse que tienen esquemas fiscales que no son equitativos horizontalmente. Por un lado se contempla la liberación del pago del ISR para las cooperativas de consumo, así como para las de ahorro y préstamo — situación que es adecuada-; y, por otra parte se grava a las cooperativas de producción, diferenciando de entre estas a las que realizan actividades del sector primario, de las que realizan otras actividades económicas. No obstante, la Ley del Impuesto Sobre la Renta (2016) incluye en el apartado de Estímulos Fiscales, una opción que resulta en la disminución del pago del ISR y en su caso en el diferimiento del mismo hasta por cinco años, lo que no es suficiente para cumplir con la obligación que tiene el Estado de impulsar el desarrollo integral de las cooperativas.

Por lo anterior, el tratamiento en materia de ISR no es el mismo, principalmente por la obligación que tienen las cooperativas de producción de pagar dicho tributo, lo que conduce a la inobservancia del postulado de equidad, que según Arrioja Vizcaíno $(2002,259)$ se cumpliría «tratando igual a los iguales y en forma desigual a los que no se encuentran en igualdad de circunstancias». De tal manera que la equidad tributaria para las cooperativas debería expresarse a partir de la equidad horizontal, dando el mismo tratamiento a sujetos de naturaleza idéntica.

La ausencia de equidad tributaria a que alude el párrafo que antecede, ha sido dirimida en los tribunales y como resultado de ello la Corte ha emitido resoluciones que buscan esclarecer el sentido de la ley y desentrañar cuál fue la finalidad del legislador para establecer la disposición y en consecuencia determinar su aplicación para las cooperativas.

Sobre el particular se puede comentar que en el Amparo en revisión 289/2001 (SCJN, 2001, 45), se alegó la inequidad entre las cooperativas de producción de servicios y las dedicadas a actividades primarias, siendo que las primeras están obligadas al pago del impuesto de conformidad con el Título II. En este tenor la SCJN argumentó que dichas cooperativas no se encontraban «material y jurídicamente» en las mismas circunstancias, por lo que no se transgredía el principio de equidad tributaria, dado que las cooperativas dedicadas a la agricultura, ganadería, silvicultura y pesca, contribuyen al desarrollo del sector primario del país, mientras que las de producción de servicios tienen una situación diferente, lo que fue suficiente para que el legislador determinara que se cumple con el principio de equidad y es válido aplicar un tratamiento tributario desigual. Tal opinión, luego se confirmaría en la jurisprudencia (SCJN, 2002), reiterando que no es inequitativo el ex- 
cluir del beneficio fiscal a las cooperativas de producción, toda vez que estas realizan actividades de asistencia profesional, técnica, académica o científica y no de producción, lo que desde la posición del juzgador es suficiente para dar un trato desigual a dichas sociedades.

Además de lo mencionado, se ha discutido en los tribunales la ausencia de equidad tributaria, por el trato diferenciado que se les ha venido otorgando a las sociedades cooperativas de consumo y producción; recordemos que las primeras se encuentran consideradas en el Título III como Personas morales no contribuyentes del ISR y en consecuencia no están obligadas al pago de dicho impuesto. De tal manera que con la tesis aislada del Amparo en revisión 174/2004 (SCJN, 2005, 350) relativa a la aplicación de la legislación en materia de ISR con vigencia en 2002, el juzgador confirmó que la diferenciación tributaria que se hace en ambas cooperativas, no viola el principio de equidad, ya que desde su perspectiva, la exención que beneficia a las cooperativas de consumo y de producción se justifica porque ambas sociedades se encuentran en: "... categorías abstractas de sujetos ubicados en situaciones objetivamente distintas, desde un punto de vista social y económico». La argumentación central se apoya en que las cooperativas de consumo suministran productos a sus socios, mientras que las de producción comercializan bienes y servicios para obtener la mayor ganancia posible. El juzgador considera que las cooperativas no se encuentran en una situación de igualdad, por tanto, no debe aplicarse el mismo tratamiento jurídico.

Como puede verse, los argumentos en los que la Corte sostiene su fallo, tiene que ver con las actividades que realizan las cooperativas y no con su naturaleza o razonamientos centrados en los principios jurídicos, especialmente los de equidad tributaria y capacidad contributiva, ya que tal como se indica en la teoría, sería este último postulado, de gran utilidad para establecer las diferencias entre los contribuyentes y conseguir un pago o exoneración equitativa. Aunado a lo mencionado, el juzgador ignora la esencia de la legislación para las cooperativas donde se menciona expresamente su carácter no lucrativo.

En consecuencia, los argumentos expuestos por la SCJN resultan triviales, toda vez que las cooperativas cumplen con una importante labor económica y social en las comunidades donde se ubican; siendo precisamente su finalidad y las disposiciones constitucionales, las que debieran ser el sustento necesario para justificar los incentivos aplicables para las cooperativas de cualquier actividad, sea esta de consumo, producción o de ahorro y préstamo.

Lo anterior se refuerza en los considerandos incluidos en el Decreto por el que se otorgan medidas de apoyo a la vivienda y otras me- 
didas fiscales $(2015,1)$, donde se justifica plenamente la labor de las cooperativas en beneficio de la sociedad y su práctica de principios de «(...) solidaridad, esfuerzo propio y ayuda mutua, con el propósito de satisfacer necesidades individuales y colectivas, a través de la realización de actividades económicas de producción, distribución y consumo de bienes y servicios; (...)».

Por tanto, el juzgador al momento de emitir su resolución, ignora el aporte que las cooperativas hacen a la sociedad a partir de su contribución al desarrollo local y a los indicadores económicos nacionales, a la educación, a la salud, al empoderamiento de las mujeres, a la conservación del medio ambiente, entre otros de igual importancia. Pero además deben considerarse otros fundamentos constitucionales que no son tomados en cuenta por el legislador al momento de emitir las normas fiscales, pues en la propia Constitución se establece la obligatoriedad del Estado para apoyar el desarrollo de estas sociedades. Por lo que se considera que las argumentaciones presentadas en las tesis y jurisprudencias previas, no son relevantes para el análisis jurídico, debido a que tal como lo indica la SCJN (1984) «La equidad tributaria significa (...) que los contribuyentes de un mismo impuesto deben guardar una situación de igualdad frente a la norma jurídica que lo establece y regula».

Por lo anterior, las cooperativas de producción debieran estar clasificadas en el Título III de la Ley del Impuesto Sobre la Renta (2016), como No contribuyentes del ISR y así cumplir con la equidad horizontal, que es la que en la práctica aplica en las cooperativas de ahorro y préstamo, así como en las de consumo, no siendo de esta manera en las de producción, donde es notoria la diferenciación al considerarlas como obligadas al pago del impuesto.

Es importante señalar que diferenciación antes mencionada, es evidente inclusive entre las cooperativas de producción de bienes y las dedicadas a la producción de servicios. Lo que podría explicarse por las acciones que se tomaron a través de la Secretaría de Hacienda y Crédito Público, para frenar el uso indebido de la figura jurídica de cooperativa de producción por empresarios poco escrupulosos, quienes se beneficiaron indebidamente de los incentivos y tratamientos preferenciales a partir de simular que llevaban a cabo actividades propias de las cooperativas, lo que posteriormente condujo a que el Congreso de la Unión reformara la Ley del Impuesto Sobre la Renta, introduciendo limitantes o atenuando los incentivos para estas sociedades, lo que no se encuentra justificado a partir de los principios jurídicos o de los preceptos constitucionales vigentes. 


\section{Conclusiones}

En diversas oportunidades se ha expresado la necesidad de que los impuestos posean una característica redistributiva, cuyo efecto final se vea reflejado en la equidad social (Gómez-Sabaini, Santiere, \& Rossignolo, 2002). En este sentido, Bárcena y Serra (2012) revelan que existen marcadas diferencias en los países de América Latina, quedando de manifiesto que los sistemas fiscales que prevalecen en las naciones - como la mexicana - se favorece la desigualdad económica y social, lo que podría equilibrarse a partir del establecimiento de incentivos tributarios (Mankiw, 2012), principalmente para aquellos ciudadanos en desventaja.

Es entonces que las cooperativas se manifiestan como el medio a través del cual es posible transformar la realidad de millones de personas, ya que por su conducto se fomenta el emprendimiento de los que menos tienen, con actividades sociales y económicas que contribuyen al desarrollo de las economías locales y que en ocasiones coadyuvan con el Estado en tareas que deben ser asumidas por este. Ya que como lo expresa Atxabal Rada (2016) en la gestión de las cooperativas no intervienen inversores externos, sino que el control se ejerce a partir de la administración de los socios, por lo que el valor económico generado es destinado al interés común, es por ello que la identidad de las cooperativas debe ser considerada al momento de fijar tributos.

En consecuencia, para otorgar un tratamiento equitativo a los contribuyentes, es fundamental atender a la equidad vertical y horizontal, esto implica reconocer las diferencias entre los sujetos de un mismo impuesto, aplicando la proporcionalidad que como principio constitucional atiende a la capacidad contributiva, pero además se trata de otorgar el mismo tratamiento a los contribuyentes que son iguales en todos los aspectos y por tanto, deben recibir un trato idéntico. Es por lo antes referido, que no se justifica dar un trato diferenciado a sociedades de la misma naturaleza, como lo son las cooperativas y que su posible diferenciación tendría que apoyarse en argumentos de equidad, lo que la Corte no hace en ningún momento.

Debe enfatizarse que en diversas resoluciones -tesis y jurisprudencias- emitidas por la SCJN, no se toma en cuenta el sentido doctrinal de la equidad, tema que incluso ya ha sido dirimido previamente (SCJN, 1984, 113) estableciendo que la «equidad radica medularmente en la igualdad ante la misma ley tributaria de todos los sujetos pasivos de un mismo tributo (...)», pero además dice, que la equidad debe ser tomada en cuenta al momento de imponer un tributo, así como la capacidad económica de cada sujeto pasivo, con lo que también se res- 
petaría el principio constitucional de proporcionalidad a que hace referencia el artículo 31-IV de la Constitución Política de los Estados Unidos Mexicanos (2017).

Aunado a lo que ya se ha expresado, puede decirse que el juzgador no acude a argumentaciones apoyadas en la capacidad económica, ya que es sabido que la mayor parte de las cooperativas han sido constituidas a partir de iniciativas de comunidades con grandes carencias económicas, las que han visto en estas sociedades la salida para solucionar sus problemas comunes.

Consecuentemente, los argumentos expresados por la Corte son banales, pues no debería sustentarse el cumplimiento del principio de equidad para las cooperativas de producción por las actividades que en ellas se realizan, pues el juzgador da por hecho que en tales sociedades se trata de obtener la máxima ganancia (SCJN, 2005, 2002), cuando en realidad no ocurre así.

Finalmente, debe insistirse en que además de los fundamentos constitucionales que avalan el fomento de las cooperativas y su trato equitativo en materia tributaria; la finalidad económica-social de las cooperativa debe ser uno de los argumentos más importantes para que el legislador contemple el otorgamiento de incentivos tributarios a los tres tipos de cooperativas, independientemente de las actividades que en ellas se efectúen y dando a cada una lo que en justicia les corresponde.

\section{Referencias bibliográficas}

ALGUACIL MARÍ, María Pilar, 2003. "Tratamiento fiscal de las cooperativas a la luz del régimen europeo de ayudas de Estado». CIRIEC-España. Revista jurídica de economía social y cooperativa, no 14: 131-181. Desde https:// dialnet.unirioja.es/servlet/articulo?codigo $=760704$

ARNAIZ AMIGO, Aurora, 1979. "Derecho cooperativo». Revista de la Facultad de Derecho de México, n. ${ }^{\circ}$ 113: 325-344. Desde https://revistascolaboracion.juridicas.unam.mx/index.php/rev-facultad-derecho-mx/article/ view/27219/24566

ARRIOJA VIZCAINO, Adolfo, 2014. Derecho Fiscal. México: Themis Editores.

ATXABAL RADA, Alberto, 2016. "La identidad cooperativa como justificación de un tratamiento fiscal diferenciado». Boletín de la Asociación Internacional de Derecho Cooperativo, no 50: 285-307. DOI: http://dx.doi.org/10.18543/baidc-50-2016pp285-307.

CRACOGNA, Dante, 2004. Las cooperativas frente al régimen tributario. En Cracogna, D. (coordinador). "Las cooperativas y los impuestos en el Mercosur». Buenos Aires: Intercoop. 
DRAE, 2014. Diccionario de la Real Academia Española, concepto de justicia. Acceso 19 de marzo de 2018. http://www.rae.es/

GÓMEZ-SABAINI, Juan Carlos, Juan José Santiere \& Dario Alejandro Rossignolo, 2002. La equidad distributiva y el sistema tributario: un análisis para el caso argentino. Santiago de Chile: Cepal.

IZQUIERDO MUCIÑO, Martha E. 2016. "Cooperativas de producción en México y reformas fiscales», Boletín de la Asociación Internacional de Derecho Cooperativo, núm. 50, pp. 103-126.

JIMÉNEZ, Juan Pablo, Juan Carlos Gómez Sabaini \& Andrea Podestá, 2010. Evasión y equidad en América Latina. Santiago de Chile: CEPAL.

JORRAT, Michel, 2011. "Evaluando la equidad vertical y horizontal en el impuesto al valor agregado y el impuesto a la renta: el impacto de reformas tributarias potenciales. Los casos del Ecuador, Guatemala y el Paraguay». Serie Macroeconomía del Desarrollo, n. ${ }^{\circ}$ 113: 1-62. Comisión Económica para América Latina y el Caribe. Santiago de Chile: Cepal. Desde https://repositorio.cepal.org/bitstream/handle/11362/5345/S1100385_ es. . $d f$ ? sequence $=1$ \&isAllowed $=y$

LARA GÓMEZ, Graciela. 2018. "Los incentivos tributarios para las cooperativas financieras de Colombia, Costa Rica y México». REVESCO, Revista de Estudios Cooperativos, núm. 127, pp. 159-180.

LARA GÓMEZ, Graciela y Amalia Rico Hernández, 2008. "Subcontratación en Cooperativas de Producción». Revista de la Cooperación Internacional. Órgano oficial de la Alianza Cooperativa Internacional, vol. 41, n. ${ }^{\circ} 2$ : 109-122. Desde http://www.biblioteca.coop/bdc/revistas/ACl/2008-2/files/ assets/basic-html/page-2.html

MANKIW, Gregory, 2012. Principios de economía. México: Cengage Learning Editores.

MEDINA CONDE, Analaura y Flores Ilhuicatzi, Uziel. 2015. «Análisis de la sociedad cooperativa y su fiscalidad en la región mixteca oaxaqueña, México». Boletín de la Asociación Internacional de Derecho Cooperativo, núm. 49, pp. 251-278.

RAWLS, John, 2010. Teoría de la Justicia. México: Fondo de Cultura Económica.

RODRIGO RUIZ, Marco Antonio, 2003 «Mandato constitucional de fomento y fiscalidad de las cooperativas». CIRIEC-España, Revista de Economía Pública, Social y Cooperativa, n. ${ }^{\circ}$ 47: 199-219. Desde http://www.redalyc. org/articulo.oa? id $=17404720$

ROJAS CORIA, Rosendo, 1984. Tratado de Cooperativismo Mexicano. México: Fondo de Cultura Económica.

STIGLITZ, Joseph, 1995. La economía del sector público (Vol. 24). Barcelona: Antoni Bosch Editor. 
Normatividad y resoluciones de la corte

CÓDIGO DE COMERCIO, 1889. Código publicado en el Diario Oficial de la Federación los días lunes 7 de octubre al viernes 13 de diciembre de 1889. Acceso el 26 de marzo de 2018. http://www.memoriapoliticademexico. org/Textos/5RepDictadura/1889CDC.html

CONSTITUCIÓN POLÍTICA DE LOS ESTADOS UNIDOS MEXICANOS, 2017. Diario Oficial de la Federación. Congreso de la Unión, México.

DECRETO POR EL QUE SE OTORGAN MEDIDAS DE APOYO A LA VIVIENDA Y OTRAS MEDIDAS FISCALES, 2015. Diario Oficial de la Federación, 26 de marzo de 2015. Secretaría de Hacienda y Crédito Público. Acceso el 28 de febrero de 2018. http://www.sat.gob.mx/informacion_fiscal/normatividad/ Paginas/otrasdisposiciones_dof2015.aspx

INEGI 2018. UMA. Instituto Nacional de Estadística y Geografía. http://www. beta.inegi.org. $\mathrm{mx} /$ temas/uma/

LEY DEL IMPUESTO SOBRE LA RENTA, 2016. Ley del Impuesto Sobre la Renta. Diario Oficial de la Federación, H. Congreso de la Unión. Acceso el 28 de febrero de 2018. http://www.diputados.gob.mx/LeyesBiblio/pdf/ LISR_301116.pdf

LEY GENERAL DE SOCIEDADES COOPERATIVAS, 1994. Diario Oficial de la Federación del 3 de agosto de 1992. Congreso de la Unión. Acceso el 28 de febrero de 2018. http://dof.gob.mx/nota_detalle.php?codigo=4723403\&f echa=03/08/1994

LEY GENERAL DE SOCIEDADES COOPERATIVAS, 2009. Diario Oficial de la Federación, H, Congreso de la Unión. Acceso el 28 de febero de 2018. http://www.diputados.gob.mx/LeyesBiblio/pdf/143.pdf.

LEY GENERAL DE SOCIEDADES MERCANTILES, 2016. H. Congreso de la Unión. Acceso el 28 de febrero de 2018. http://www.diputados.gob.mx/Leyes Biblio/pdf/144_140316.pdf

SCJN, 1984. Proporcionalidad y equidad tributarias establecidas en el artículo 31, Fracción IV, Constitucional. Segunda Sala, Semanario Judicial de la Federación, Volumen 187-192, Primera parte, Jurisprudencia, pág. 113. http://sjf.scjn.gob.mx/sjfsist/Documentos/Tesis/1012/1012005.pdf

SCJN, 2001. Renta. El artículo 10-B Segundo párrafo, de la Ley que regula el impuesto relativo, al no considerar a las sociedades cooperativas de producción de servicios en la exención del pago de este tributo, no transgrede el principio de equidad tributaria. Amparo en revisión 289/2001. Segunda Sala, Semanario Judicial de la Federación y su Gaceta, Tomo XIV, noviembre de 2001, Tesis 2. ${ }^{a}$. CCXV/2001, pág. 45. http://sjf.scjn.gob.mx/sjfsist/ Documentos/Tesis/1012/1012012.pdf

SCJN, 2002. Renta. La exención a que se refiere el artículo 10-B, segundo párrafo, de la ley que regula el impuesto relativo, no transgrede el principio de equidad tributaria por excluir de ese beneficio fiscal a las sociedades cooperativas de producción de servicios. Segunda Sala, Semanario Judicial de la Federación y su Gaceta, Tomo XV, marzo de 2002, Te- 
sis 2.a/J. 16/2002, pág. 297. https://sjf.scjn.gob.mx/sjfsist/Documentos/ Tesis/1001/1001973.pdf

SCJN, 2005. Renta. Los artículos 93 y 95, fracción VII, de la ley del impuesto relativo, al no incluir a las sociedades cooperativas de producción en la exención prevista para las de consumo, no violan el principio de equidad tributaria (legislación vigente en 2002). Segunda Sala, Semanario Judicial de la Federación y su Gaceta, Tomo XXI, febrero de 2005, Tesis 2. ${ }^{a} \mathrm{XV} / 2005$, pág. 350. http://sjf.scjn.gob.mx/SJFSist/Documentos/Tesis/179/179204.pdf 


\section{Derechos de autor}

El Boletín de la Asociación Internacional de Derecho Cooperativo es una revista de acceso abierto lo que significa que es de libre acceso en su integridad inmediatamente después de la publicación de cada número. Se permite su lectura, la búsqueda, descarga, distribución y reutilización legal en cualquier tipo de soporte sólo para fines no comerciales y según lo previsto por la ley; sin la previa autorización de la Editorial (Universidad de Deusto) o el autor, siempre que la obra original sea debidamente citada (número, año, páginas y DOI si procede) y cualquier cambio en el original esté claramente indicado.

\section{Copyright}

The International Association of Cooperative Law Journal is an Open Access journal which means that it is free for full and immediate access, reading, search, download, distribution, and lawful reuse in any medium only for non-commercial purposes, without prior permission from the Publisher or the author; provided the original work is properly cited and any changes to the original are clearly indicated. 